\title{
Student's Dynamics of Didactic Competence during the "Internship of Preparation for Professional Life” in Physical Education and Sports. Evolution of Pre and Post Active Planning
}

\author{
Nabila Bennour ${ }^{1}$, Makram Zghibi ${ }^{2}$, Sheima Jayari ${ }^{3}$, Najmeddine Ouessleti ${ }^{4}$ \\ ${ }^{1}$ UMR EFTS Mirail University of Toulouse II, Toulouse II, France \\ ${ }^{2}$ University of Franche-Comté, Besançon, France \\ ${ }^{3}$ Université of Tunis, Tunis, Tunisia \\ ${ }^{4}$ Higher Institute of Sports and Physical Education, Kef, Tunisia \\ Email: nabilabennour2007@yahoo.fr
}

Received February $13^{\text {th }}$, 2013; revised March $14^{\text {th }}$, 2013; accepted March $28^{\text {th }}, 2013$

\begin{abstract}
Copyright (C) 2013 Nabila Bennour et al. This is an open access article distributed under the Creative Commons Attribution License, which permits unrestricted use, distribution, and reproduction in any medium, provided the original work is properly cited.
\end{abstract}

\begin{abstract}
This study encourages decision making in the field of university training of Physical Education and Sports teachers. It consists in observing and analysing the evolution of pre and post active planning of intern students and identifying their didactic competence during the internship period. Following a qualitative approach a corpus of seventy-two documents prepared by six intern students at the Higher Institute of Sports and Physical Education (ISSEP) in Kef was analyzed. The analysis of these document is based on "guiding questions" constructed from the normative didactic. The analysis of the data allowed inferences about the didactic competence observed. Case analysis and multi-case analysis revealed a static trend in the evolution of specific competence in planning. The appearance of recurrent difficulties in some specific competence reveals the thesis of a "survival strategy" developed by intern students. The in-depth analysis of the preparations also revealed an ineluctable effect of "pedagogy by objectives" on the logic and nature of planning and balance sheets of lessons developed. In addition, the study refutes the hypothesis of the suspected effect of the internal logic of sports activities on the nature of planning and unveils a "traditional" conception of teaching physical education.
\end{abstract}

Keywords: Professional Competence; Didactic Competences; Planning

\section{Introduction}

The teacher's training of Physical Education and Sports provided by the Tunisian ISSEP is characterized by a double profile: it has both an academic character and a practical professional character. Practical teaching is assured mainly during the second cycle of training and it takes place in schools as a course called "internship of preparation for professional life" (Decree No. 2006-591 on 1 March 2006). During this internship, intern students are expected to acquire a bundle of disciplinary, pedagogical and didactic competence deemed necessary for their future teaching role (Desbiens, Borges, \& Spallanzani, 2009).

However, in practices, many trainers and inspectors noted that under the constraints of real class context questions of what to teach and how to organize and plan are relegated to second place ceding place to more vital and heavy concerns for the students, namely the material and human organization, the classroom control and time management.

Now, several researchers (Amade-Escot, 1989; Marsenach, Dhellemmes, Goirand, Lebas, Léziart, Latch, Roche, \& Roussel, 1991) suggest that the control of all the aspects of the real situation happens in large part by a good organization of teaching content and a good planning. The latter is understood in the context of our research as a cognitive activity organization related to the activity of preparing lessons. It characterizes, according to Tochon (1993), the anticipation activity of the teacher during the pre-active phase and regulatory activity during the post active phase.

Therefore, we found it interesting to observe more closely the process of acquiring didactic competence taking place during the internship. We decided to study the evolution of didactic competence required in the preparation of teaching sequences through the analysis of the students' prepared lessons. This clearly shows our interest in didactic competence that is involved in planning and which is defined as "the dominant phase of the teacher activity” (Riff \& Durand, 1993).

Through this qualitative and descriptive study, we hope to clarify the real effect of the "internship of preparation for professional life" on the acquisition of some didactic competence which is primarily related to the axis "teacher knowledge". Indeed, the didactic intervention is strongly linked to competence related to the construction and progression of learning situations and the elaboration of the lessons balance sheets.

\section{Aims and Research Questions}

This research encourages decision making in the field of university training of Physical Education and Sports. It has 
mainly a social function that manifests itself in the role of reading the reality to inform us of the knowledge (competence) with which we must equip intern students and eventually in the absence of official texts governing the content of the internship to invite us to reflect on the establishment of a training project to promote the acquisition of such competence. This research aims to analyze how intern students organize the motor situations in relation to the different physical and sport activities taught (gymnastics, volleyball, athletics, etc.) but also how these students develop their lesson balance sheets. We expect therefore to identify the difficulties encountered in their planning activity and to reveal some gaps ignored by the trainers. Our research is organized in an effort to improve and evaluate the internship suggesting some improvement and monitoring of the internship which can be set up in initial training.

The research aims to answer three basic questions. The first is related to the evolution of the acquisition of didactic competence among intern students. The second concerns the progresses made by these students as to the third it is related to the persisting difficulties.

\section{Methodology}

We opted for a qualitative approach (Miles \& Huberman, 1991). We thus conducted a documentary analysis of a case study and a subsequent multi-case study.

The case study was conducted on six students, three from each sex registered in the fourth year Master of Physical Education and Sports in the ISSEP of Kef and followers of an internship at four different host institutions. For each student we coded the name by these initials: BM, BN, CW, GH, GI and JB. We selected twelve documents which were numbered according to their appearance in the cycle: six documents for lesson preparation with their six respectives balances sheets that have learning objectives.

The content analysis of the participants' production is based on guiding questions developed from a synthesis of many kinds of didactic competence defined in the conceptual framework (both from the didactic scientific and normative references) as a qualitative indicators of both selected didactic competence: planning of motors situations and elaboration of balance sheets lessons. The analysis of the data allowed inferences about didactic competence observed.

We opted for descriptive matrixes (Lessard-Hébert, Goyette, \& Boutin, 1996). Two levels of condensation were carried out.
At a first level of data condensation, lesson by lesson, matrixes correspond to checklists that break the variables of the study in several indicators. For each intern student and for each document, data coding from a content analysis takes the form of a table with two variables to consider: planning of motors situations and elaboration of balance sheets lessons.

The used methodology consists in analyzing the content of the collected planning documents. For each lesson, we identified three headings that seem a necessary safeguard to ensure coherence of the analysis:

- Guiding questions are presented as a tool for data querying.

- The facts are presented as variable inferences. They are answers from the findings.

- The inference, as stated by Bardin, is a "logical operation, in which we admit a proposal by virtue of its connection with other proposals already held to be true” (1996: p. 43). It is a term to describe induction from facts.

Data condensation matrixes are presented in Table $\mathbf{1 .}$

At a second level of data condensation, the procedure consists in assembling for each student the most significant traits of planning motor situations and elaborating balance sheets lesson. This second level is presented as chronological matrix. It aims at summarizing, lesson by lesson, the inferences made from the first level of data condensation by highlighting the salient traits of the didactic competence of pre active planning (motors situations) and post active one (balance sheets of lessons). From this inferential analysis we will make the evolutions, the breaks and the stabilities of the studied sub-competence.

The presentation of results concerns students as demonstrated by Table 2 .

At the level of the case study, graphic representations are made in order to assess general trends in the evolution of sub-competence during the lessons for each of the cases studied. We accounted the sub-competence manifestations as positive responses in one series and the absence of sub-competence manifestations as negative responses in a second one.

At the level of multi-case studies, a general graphic representation combines the responses of the six participants to the eight sub-competences in all scheduled lessons. The positive and negative responses were summed and converted to a percentage.

\section{Results}

From the sub-competence inferences, we have observed and

Table 1.

Descriptive matrix of data condensation.

\begin{tabular}{ll}
\hline & \multicolumn{1}{c}{ Guiding questions } \\
\hline & Are selected Educational objectives relevant to the lesson objectives? \\
& Are constructive tasks consistent with the fixed educational goals? \\
Planning motors & Is there coherence between the observed tasks at different moments of the lesson? \\
situations & Are motor situations inscribed in a progression? \\
& $\begin{array}{l}\text { Is the time allocated to each task proportional to its difficulty? } \\
\text { Do the proposed tasks take into account the variables of regulations? } \\
\text { Is there a finding and interpretation of the obstacles encountered by students } \\
\text { during the lesson? Are they taken into consideration in the next lesson? } \\
\text { balance sheets }\end{array} \quad \begin{array}{l}\text { Are findings, interpretations, and perspectives related to the following areas: learning activities, } \\
\text { didactic path and the relationship between teacher/student? }\end{array}$ \\
\hline
\end{tabular}


Table 2.

Chronological matrix of data condensation.

\begin{tabular}{|c|c|c|}
\hline & Guiding questions & Inferences summaries \\
\hline & & Lesson 1 \\
\hline & & Lesson 2 \\
\hline & & Lesson 3 \\
\hline & Questionil 1 & Lesson 4 \\
\hline & & Lesson 5 \\
\hline & & Lesson 6 \\
\hline & Interpretation & \\
\hline & Question 2 & \\
\hline \multirow[t]{13}{*}{ Planning motos situations } & Interpretation & \\
\hline & Question 3 & \\
\hline & Interpretation & \\
\hline & Question 4 & \\
\hline & Interpretation & \\
\hline & Question 5 & \\
\hline & Interpretation & \\
\hline & Question 6 & \\
\hline & Interpretation & \\
\hline & & Lesson1 \\
\hline & & Lesson 2 \\
\hline & & Lesson 3 \\
\hline & Question 1 & Lesson 4 \\
\hline \multirow[t]{5}{*}{ Elaboration of balance sheets } & & Lesson 5 \\
\hline & & Lesson 6 \\
\hline & Interpretation & \\
\hline & Question 2 & \\
\hline & Interpretation & \\
\hline
\end{tabular}

commented on the evolutions case by case, then in a second time, a multi-case comparison. These two sources of information have enabled general trends that had been analyzed in depth to identify and address the observed progresses and the recurrent difficulties. All of these results have led to a more global vision and made inferences about the internship effect.

\section{Case Analysis}

To understand the dynamic of sub-competence in the planning of each studied case, our observation focused on the presence or absence of manifestation of sub-competence involved and their respective proportions in all the documents selected for analysis.

- In the BM case, we noticed that the sub-competence manifestation increased in a linear way until the sixth lesson. A break of that dynamic appeared at the seventh lesson through a qualitative leap at the ninth lesson. Note, however, that the maximum threshold according to BM did not exceed five sub-competences of the eight expected.

- In the case of BN we noted a constant absence of subcompetence manifestation. During lessons 7 and 12, we as- sisted to a progression that remains insufficient referring to the very small number of the manifested sub-competence.

- In the case of CW, GI, GH and JB, we found a chaotic, weak and irregular evolution of the sub-competence manifestation.

\section{Multi-Case Analysis}

The analysis showed a real evolution in manifestation of a considerable number of sub-competences according to BM. The regularity and the importance of this evolution are not identified in the remaining cases. CW presents a less pronounced evolution, with a threshold of appearance around three of eight sub-competences per lesson. JB and GH have similar tracings that do never exceed two of eight sub-competences. Compared to $\mathrm{BM}$, their evolutions prove to be insignificant. GI and $\mathrm{BN}$ do not manifest any evolution.

As shown in Figure 1, the best manifestation of sub-competence was recorded for $\mathrm{BM}$ with $46 \%$, followed by a fairly large difference for CW with 29\%, 21\% for GH and JB with $17 \%$. GI and BN have planning that do not express the expected sub-competence. 


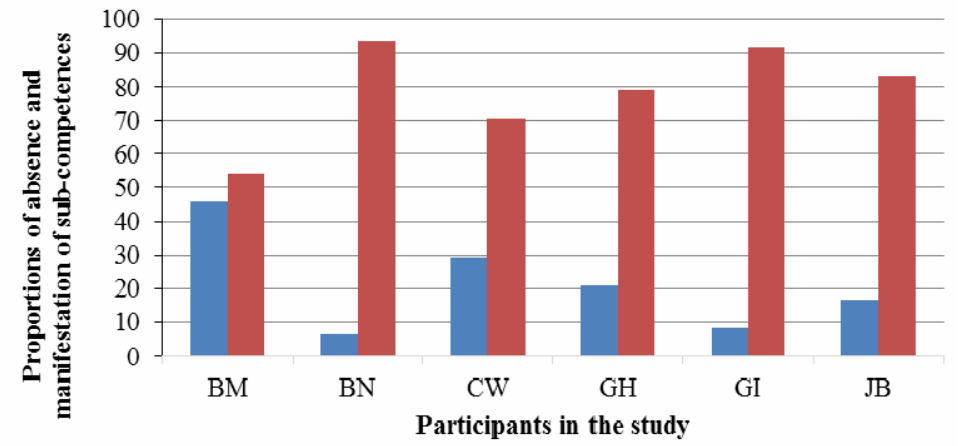

- Manifestation of sub-competences

- Abscence of sub-competences manifestation

Figure 1.

Proportions of responses in all cases and lessons analyzed.

The general graphic representation below shows a reduced gap between positive and negative responses according to BM. This gap is more pronounced in other cases and goes up to $86 \%$ according to BN.

\section{Observed Progress and Recurrent Difficulties}

The difficulty of finding a general common trend summarizing the evolution of six studied cases leads us to a deep analysis of the revealed evolutions. So we studied the progress and the observed difficulties for each sub-competence.

The achieved progress is observed in four sub-competences: the consistency of the warm-up, the relevance of objectives, the coherence of tasks and the progressivity of situations. Recurring difficulties resulting from a lack of progress are identified, in the sub-competence related to the consistency of the return to calm, the proportionality of time, the regulation of tasks, and the elaboration of balance sheet lessons.

Case analysis and multi-case analysis revealed a static trend in the evolution of specific competence in planning for the majority of participants (five out of six students). In fact only one case presented a partial evolution in a limited number of specific competence. The absence of a clear evolution and the stagnation of planning quality and balance sheets help to doubt or to question the systematic positive effects of internship on the acquisition and evolution of specific competence related to the planning and elaborating of balance sheets lessons. The appearance of recurrent difficulties in some sub-competence supports the thesis of a "survival strategy" developed by the intern student which consists to promote the furnishing of preparations by learning situations regardless of their learning effects and consistent teaching and which ultimate objective is to deliver a content around which the lesson turns.

\section{Interpretation}

As trying to understand these results from the research data, we adopted two interpretative hypotheses, one relating to the content and the other to the learner.

The first interpretative hypothesis is to connect didactical choices according to the internal logics of the physical and sport activities. We analyzed the characteristics of prescribed motor situations and their logical progression depending on the taught activity. The aim of this analysis is, on the one hand, to identify the general trends in the choice of situations and their logical progression, and on the other hand, to examine the possible effect of the internal logics of the activities on students' choice.

The analysis detects a predominance use of "control objectives" (90\%) and a "cumulative logic" (33.33\%) in teaching collective sports, as well as "defined tasks" (65.91\%) and "situations under motors solution" (56.52\%) in individual sports such as gymnastic.

Based on the work of Parlebas and Dugas (1998) on "the internal logic" of physical and sport activities, on theories supported by Grehaigne, Caty and Marle (2004) in teaching collective sports and on the works of Bourgeois (1998) on the internal logic of gymnastic activities, this predominance seems to contradict the effect of the internal logics of activities on the students' choice.

These choices could be explained by the suspected effect of the pedagogy by objectives, exclusively centered on the observable and measurable behavior. The transfer of relevant learning to the cognitive sphere and the creativity of the emotional are difficult to observe and measure beyond the fact that they are relegated to a second plan. This pedagogical approach of physical and sport activities seems to affect the choice of intern students and contributes to the restriction of their technical and pedagogical knowledge.

The second interpretative hypothesis is to connect didactical choices to the students' conceptions of teaching physical and sport education. Apart from the certain interest in confronting some progressive logics to internal logics of physical and sport activities taught, the logic of tasks progression can be a good indicator of students' conceptions of education, the learner and the activity. Like the inferences made by Amade-Escot (1989) on the basis of a typology of the motor situations used by teachers, inference conceptions based on the logics of progressivity used by intern students seems possible. The use of this indicator in the study of intern student planning is interesting.

The study of different lessons revealed that the trends in student's didactical choices are not random and seem to arise from a traditional conception of teaching physical education. Indeed, the conceptions used in the student's planning belong to a characteristic teaching model of "the yesterday teaching" de- 
scribed by Marsenach, Dhellemmes, Goirand, Lebas, Léziart, Latch, Roche and Roussel (1991).

The planning of intern students is characterized by a formal conception of teaching content focused on the external form of actions regardless of their production context. The proposed content refers to practitioner's actions of a very high level and they are offered to pupils regardless of their levels. The didactic treatment of activities shows essentially a chronological cut of sportive gestures; each subject makes the object of a specific learning. The organization of contents seems to be based on the idea that it is through successive accumulation and juxtaposition that pupils construct their knowledge. The situations offered to pupils are gridded by success criteria designed to reduce the differences between pupils with reference to gestural models.

\section{Conclusion}

The organization of a training action is designed to lead to acquiring competences indicating the subject's adaptation to the environment with which it was confronted. Although several authors (Blanchard-Laville \& Nadot, 2001) agree that all kinds of professional competence constituting a referential could not be fully acquired at the end of initial training. It is quite legitimate to expect the premises of adaptation that manifest through reappearance even if it is an irregular competent behavior. This means in our case a coherent and structured planning. Reminding also that our analysis focused on an average superior than $50 \%$ of the planned lessons, which represents a sufficient corpus to draw conclusions about the overall effect of the internship. We can also say that the internship had little effect on the acquisition of competence in planning teaching sequences. The study of workload, procedures and training content during the internship in a subsequent study could shed new lights on this provisional finding.

In a remedial perspective, at a final step can be considered and lead to a didactic engineering research, which aim is to build proposals for the internship and even design strategies and principles of training in an attempt to exceed gaps shown by our research.

\section{REFERENCES}

Amade-Escot, C. (1989). Teaching Strategy in EPS: Content proposed design learning opportunities and differentiation. In G. Bui-Xuan, P. Boyer, P. Chifflet, \& Y. Léziart (Eds.), Methodology and didactics of physical education and sports (pp. 119-130). Grenoble: AFRAPS.

Bardin, L. (1996). The content analysis. Paris: PUF.

Blanchard-Laville, C., \& Nadot, S. (2001). Research report on the training of teachers through monitoring cohorts. Research supported by the IUFM Britain and Versailles.

Bourgeois, M. (1998). Educational gymnastics, gymnastics for students: the joy of learning. Paris: PUF.

Decree No. 2006-591 of 1 March 2006. Establishing a general framework of the system of studies and the conditions for obtaining national diploma in physical education and sports professions awarded by higher institutes of the Ministry of Youth, Sports and physical education.

Desbiens, J.-F., Borges, C., \& Spallanzani, C. (2009). Invest in training people teaching the course related to teaching an instrument for professional development. Education and Francophonie, 37, 6-27.

Grehaigne, J. F., Caty, D., \& Marle, P. (2004). The contribution of the notion of configuration of the game didactics sports. In G. Carlier (Ed.), If we speak of the pleasure of teaching physical education. (pp. 167-179). Montpellier: AFRAPS.

Huberman, M., \& Miles, M. B. (1991). Analysis of qualitative data. Collection of new methods. Paris-Brussels: De Boeck University.

Lessard-Hébert, M., Goyette, G., \& Boutin, G. (1996). The qualitative research foundations and practices. Montreal: Ed News.

Marsenach, J., Dhellemmes, R., Goirand, P., Lebas, A., Léziart, Y., Latch, M., Roche, J., \& Roussel, F. (1991). EPS: What teaching? Didactics. Paris: NPRI.

Parlebas, P., \& Dugas, E. (1998). Transfer learning areas and motor action. EPS Balance Sheet, 27, 41-47.

Riff, J., \& Durand, M. (1993). Planning and decision-making among teachers. Results from studies in physical education and sports, analyzes and perspectives. French magazine pedagogy, 103, 28-34.

Tochon, F. V. (1993). The teacher expert, the expert teacher (pp. 69-89). Paris: Nathan. 